\title{
Potential forest fire risk evaluation in Poland
}

\author{
Ryszard Szczygieł, Mirosław Kwiatkowski, Bartłomiej Kołakowski 凶, Józef Piwnicki \\ Forest Research Institute, Laboratory of Forest Fire Protection, Sękocin Stary, Braci Leśnej 3, 05-090 Raszyn, Poland, \\ e-mail: b.kolakowski@ibles.waw.pl
}

\begin{abstract}
The term forest fire risk means the existence of such conditions that would make possible the occurrence of a fire in the forest environment. The base for the effectiveness of a forest fire protection system is the evaluation of the forest fire risk followed by adequate organization of the system. This article presents methods for determination of the forest susceptibility to fire known as potential forest fire risk. The below presented methods were developed by Forest Research Institute as the results of the projects commissioned by the General Directorate of State Forests. The forest fire risk category and stand flammability classes are the methods included here. The forest fire risk category was elaborated already in 1975 for the first time. Until today, after the last modification in 2008, it is the fundamental document for the polish forest fire protection system. The purpose of this modification was to increase the determination accuracy of the fire risk category of all polish forest, regardless of its ownership type and at the different administrative level. The categorization method, however, doesn't reflect the fire risk in micro scale. The attempt to solve that problem was made in 2018 while developing the methodology of stand flammability classes. It was assumed that ground cover fuel models will be developed for the most flammable forest habitat types including ground cover types, dominant species, age class and geographical localisation.
\end{abstract}

\section{KeY WORDS}

forest fire risk categorization, stand flammability classes, potential forest fire risk, forest fuel models

\section{INTRODUCTION}

The potential forest fire risk, expressed by forest fire risk category, is the basic premise for strategic planning of any actions linked with forest fire protection, both when it comes to forest fire prevention and operational action of fire and rescue units. It also plays a decisive role when the allocating funds for fire protection system also affects the scope of funding, for example, from the EU funds. The obligation of classifying the forest fire risk was imposed on member countries by the Council Regulation 2158/92 of 23 July 1992 regarding protection against forest fire in the European Union.

The classified area must correspond to the administrative area, at least to be at the same size as sub region - the group of counties (III NTS level). The forest fire risk category includes forests with a similar level of susceptibility to fire, determined on the basis of the frequency of fires, stand and climatic conditions, as well as anthropogenic factors. The current classification enables to determine forest fire risk also for a larger for- 
est area of the county, sub region and voivodeship or regional directorate of State Forests. However, there is a lack of method for determining forest fire risk at the level of sub compartment, compartment or forest range.

Currently, two functioning levels of forest mapping in terms of fire risk can be distinguished:

1. National level - regional directorate of State Forests classification (voivodeship, sub regions) according to the forest fire risk category.

2. Regional level - forest district (counties) classification according to the forest fire risk.

While this way of mapping the forest fire risk in the area of regional and global levels with general ranges can be used to fulfil its role and the purpose of meeting the requirements, in the case of a forest district, it does not provide the possibility to characterize differentiated fire danger. To fulfil this gap, the method of classification of forest flammability according to the forest habitat types and soil cover types was developed as a result of the research project 'Development of forest fuel models according to the forest habitat and soil cover types' by the Forest Research Institute.

\section{Material AND MEthods}

\section{Forest fire risk category}

Based on the available literature and analysis of the applied criteria for classification of forests in terms of fire risk, in particular in the European Union, it was assumed that the developed rules should be uniform and allow their application regardless of the level of administrative division of the country. In order to be able to make an objective assessment of any elements adopted for the classification of the forest fire risk, regardless of the size of the area to which it relates (there is a very large surface diversity, e.g., between the forest district and sub region or voivodeship), it was assumed that the reference area (when analysing individual classification criteria and depending on the need) will always be the same size of forest area, as in the European Union.

In order to select the criteria for classification of forests in terms of fire risk, four groups of parameters were selected, that is,

- occurrence of fires,

- stand factors
- anthropogenic factors,

- climatic factors.

The selection of the criteria characterizing the occurrence of forest fires was guided by the following assumptions:

1. The analysis covered fires over a period of 5 years (2002-2006).

2. The list of elements accepted for analysis has been extended in relation to those included in the currently applicable method of forest fire risk categorization.

3. The occurrence of fires depending on climatic, environmental and anthropogenic factors was assessed.

4. Due to the lack of detailed data on the locations of fires in forests of other forms of ownership, the analysis of the impact of forest stand factors was carried out on the basis of data of forest area managed by the State Forests National Forest Holding.

5. All analyses took into account the occurrence of forest fires in relation to 1000 ha of forested land in a given area.

The analysis of the occurrence of forest fires depending on individual factors was performed using a one-way correlation of fire density (average annual number of fires per 1000 ha of forest area) depending on the value of these factors. Examples of correlation results of forest fires' occurrence (on average in the period of 2002-2006 per 1000 ha of forest area) depending

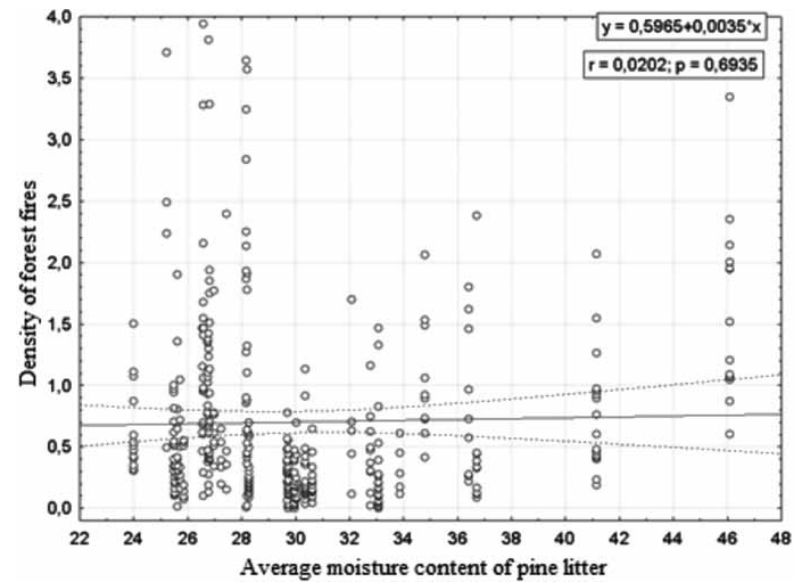

Figure 1. The occurrence of forest fires in relation to the average moisture content of pine 
on the average moisture content of pine litter at $9.00 \mathrm{am}$ during the fire season are presented in Figure 1.

\section{The stand flammability classes}

The basis for the classification of forest flammability was the analysis of the occurrence of fires in the State Forests in the years 2007-2017. When developing it, the number of fires and the burnt area were taken into account, in relation to the area occupied by individual forest types and soil cover types, calculating the flammability index. This indicator was the quotient of the share of fires or burnt area and the share of given forest habitat types. In the case of the number of fires, only those compartments in which the fire broke out were taken into account, while for the burnt area, the total area covered by the fire was scrutinized. These data were referred to the current information about the area of stands growing in individual forest habitats and the types of soil cover obtained from detailed data regarding all the compartments in whole country stored in the Forest Data Bank. Classification of stands in terms of fire risk will allow its assessment at the compartment level and the creation of a Forest Numerical Map layer with precise mapping of the fire risk. While developing the final classification method, the weight of individual indicators was dependent on the correlation strength of fire density or burnt area and the occurrence of selected types of forest stands. An example of the dependence of the number of fires on the share of flammable forest habitat types is shown in Figure 2.

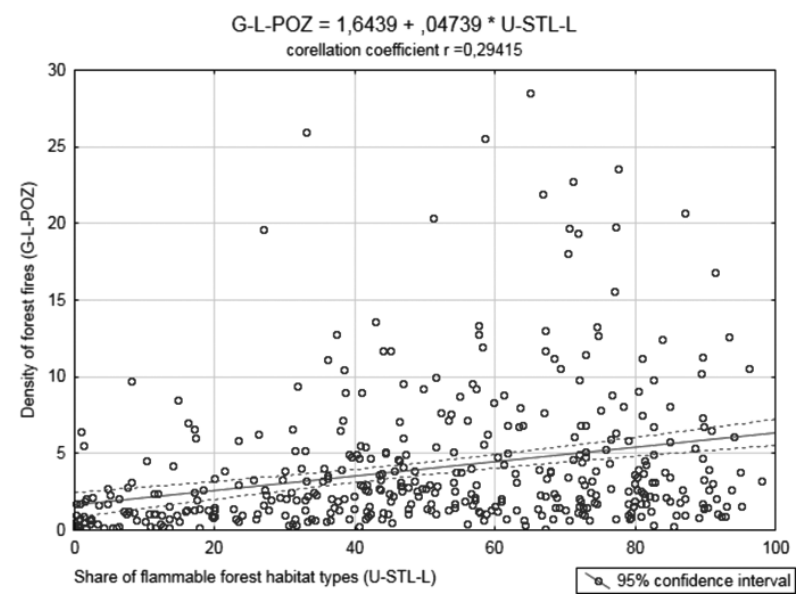

Figure 2. The correlation between density of fires (GL - POZ) and share of forest habitat types (U-STL-L)

\section{Results}

Fire risk categorization at the national and regional level is made on the basis of the assigned fire frequency ranks, forest stand conditions, climatic conditions and anthropogenic factors, determining the category of forest fire risk. The category is determined for the classified area once every 10 years on the basis of the sum of points resulting from the formulas based on statistical analyses for the following four parameters:

1) the average annual number of forest fires within the last ten years per $10 \mathrm{~km}^{2}$,

2) the percentage share of the stands growing on the following habitats: dry coniferous, fresh coniferous, fresh mixed coniferous, moist coniferous, moist mixed coniferous, and riparian forest,

3) average relative air humidity (measured at a height of $0.5 \mathrm{~m}$ ) and the percentage share of the number of days with moisture content of pine litter (Pinus sylvestris L.) less than 15\% at 9:00 a.m.,

4) average number of inhabitants per $0.01 \mathrm{~km}^{2}$ of forest land.

The number of points for the average annual number of forest fires within the last 10 years per $10 \mathrm{~km}^{2}$ is calculated according to the following equation:

$$
\mathrm{Pp}=12.5 \log (11.2 \mathrm{Gp}+0.725)+1.5
$$

where:

$\mathrm{Gp}$ - the average, annual number of forest fires within the last 10 years per $10 \mathrm{~km}^{2}$.

If the result is greater than 24 , it should be considered as 24 .

The number of points for the percentage share of the stands growing on the following habitats: dry coniferous, fresh coniferous, fresh mixed coniferous, moist coniferous, moist mixed coniferous and riparian forest is calculated according to the following equation:

$$
\mathrm{Pd}=0.01 \mathrm{Us}
$$

where:

Us - the sum of the percentage share of the stands growing on the following habitats: dry coniferous, fresh coniferous, fresh mixed coniferous, moist coniferous, moist mixed coniferous, and riparian forest. 
The number of points for the average relative air humidity (measured at a height of $0.5 \mathrm{~m}$ ) and the percentage share of the number of days with pine litter humidity (Pinus sylvestris L.) less than 15\% at 9:00 a.m. is calculated according to the following equation:

$$
\mathrm{Pk}=0.221 \mathrm{Uds}-0.59 \mathrm{Wp}+45.1
$$

where:

$\mathrm{Wp}$ - average relative air humidity at 9:00 a.m.

Uds - percentage share of the number of days with pine litter humidity (Pinus sylvestris L.) less than $15 \%$ at 9:00 a.m.

For the above calculation, the average values of the last 5 years should be used (for the fire season period when forest fire risk forecasting is conducted) taken from the closest meteorological measuring point of the prognostic network.
If the result is greater than 9 , it should be considered as 9 .

The number of points for the average number of inhabitants per $0.01 \mathrm{~km}^{2}$ of forest land is calculated according to the following equation:

$$
\mathrm{Pa}=2.46 \log (0.0461 \mathrm{Gz})+5.16
$$

where:

$\mathrm{Gz}$ - average number of inhabitants per $0,01 \mathrm{~km}^{2}$ of forest land

If the result is greater than 7 , it should be considered as 7 .

The rules for classifying the forest area to the fire risk category depending on the sum of points awarded for individual criteria are presented in Table 1.

Figure 3 presents the results of the forest fire risk categorization at the level of forest districts.

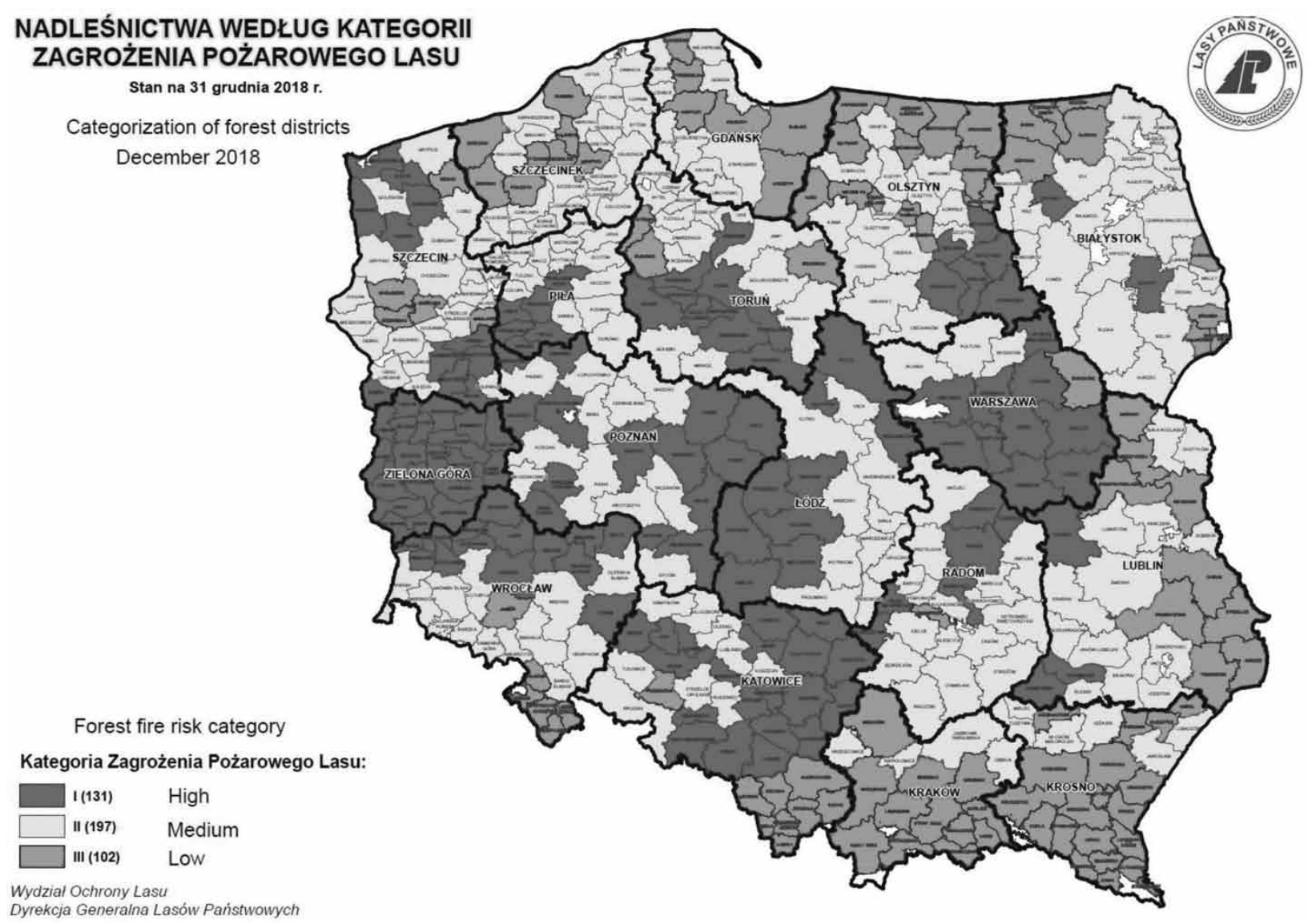

Figure 3. Forest fire risk category of forest districts 
Table 1. The rules for classifying the forest area to the fire risk category depending on the sum of points awarded for individual criteria

\begin{tabular}{|c|c|}
\hline Total number of points & Forest fire risk category \\
\hline$\geq 25$ & I (high risk) \\
\hline$<25 \mathrm{i}>15$ & II (medium risk) \\
\hline$\leq 15$ & III (low risk) \\
\hline
\end{tabular}

The forest fire risk category determines the distribution of financial resources and the organization of the forest fire protection regarding early detection, alarm and communication network, density of fire trails, water supplying points, and suppression tools.

The classification of flammability of forest habitat types and fuel models developed as the result of the project implementation allows for mapping forests in terms of their fire characteristics at the compartment level. This is the fulfilment of the requirements of Directive 2007/2/EC of the European Parliament and of the
Council of March 14, 2007 on the creation of Spatial Infrastructure in the European Union (INSPIRE), which is implemented in Poland by the Ministry of Environment. One of the assumed results of the implementation of the directive is to provide the possibility to map forest fire risk.

The analysis of occurrence of forest fires in the period 2007-2017 on the basis of which the rules for the classification of stands were developed shows the clear dominance of the three forest habitat types both in terms of the number of fires and the burnt area. These are habitats of fresh mixed coniferous forests, fresh coniferous forests and fresh mixed broadleaved forests. This dominance of the occurrence of fires is largely related to the size of the area occupied by these habitats. Flammability indices for both the number of fires and the burnt area give much more reliable information about the flammability of habitats. Table 2 presents the occurrence of fires depending on the forest habitat types and values of flammability indexes. Table 3 shows the occurrence of fires by type of soil cover.

Table 2. The occurrence of fires depending on forest habitat types and flammability indices

\begin{tabular}{|c|c|c|c|c|c|}
\hline \multirow{2}{*}{ Forest habitat type } & \multirow{2}{*}{$\begin{array}{c}\text { Share of total } \\
\text { stand area } \\
{[\%]}\end{array}$} & \multirow{2}{*}{$\begin{array}{c}\text { Share of number } \\
\text { of forest fires } \\
{[\%]}\end{array}$} & \multirow{2}{*}{$\begin{array}{c}\text { Share } \\
\text { of burnt area } \\
{[\%]}\end{array}$} & \multicolumn{2}{|c|}{$\begin{array}{c}\text { Flammability index according } \\
\text { to habitat type }\end{array}$} \\
\hline & & & & $\begin{array}{l}\text { for number of } \\
\text { fires }\left(W_{S L}\right)\end{array}$ & $\begin{array}{l}\text { for burnt area } \\
\qquad\left(W_{S P}\right)\end{array}$ \\
\hline $\mathrm{Bb}-$ bog coniferous forest & 0.15 & 0.06 & 0.34 & 0.39 & 2.28 \\
\hline $\mathrm{BMb}-$ bog mixed coniferous forest & 0.63 & 0.39 & 0.51 & 0.62 & 0.80 \\
\hline BMśw - fresh mixed coniferous forest & 23.66 & 32.99 & 26.31 & 1.39 & 1.11 \\
\hline BMw & 4.44 & 7.06 & 9.56 & 1.59 & 2.15 \\
\hline Bs - dry coniferous forest & 0.17 & 0.58 & 2.25 & 3.40 & 13.17 \\
\hline Bśw - fresh coniferous forest & 19.72 & 28.90 & 28.22 & 1.47 & 1.43 \\
\hline $\mathrm{Bw}-$ moist coniferous forest & 0.61 & 0.93 & 4.42 & 1.53 & 7.27 \\
\hline $\mathrm{L} 1$ - riparian forest & 0.47 & 0.31 & 0.38 & 0.65 & 0.80 \\
\hline $\mathrm{LMb}$ - bog mixed broadleaved forest & 0.73 & 0.15 & 0.14 & 0.20 & 0.20 \\
\hline LMśw - fresh mixed broadleaved forest & 19.07 & 14.54 & 11.79 & 0.76 & 0.62 \\
\hline $\mathrm{LMw}$ - moist mixed broadleaved forest & 3.82 & 3.55 & 3.97 & 0.93 & 1.04 \\
\hline Lśw - fresh broadleaved forest & 9.79 & 3.52 & 3.93 & 0.36 & 0.40 \\
\hline Lw - moist broadleaved forest & 1.95 & 0.62 & 0.73 & 0.32 & 0.38 \\
\hline $\mathrm{Ol}$ - alder forest & 1.79 & 0.41 & 0.55 & 0.23 & 0.30 \\
\hline $\mathrm{O} 1 \mathrm{~J}$ - alder-ash forest & 0.81 & 0.12 & 0.09 & 0.14 & 0.11 \\
\hline
\end{tabular}


This index is the quotient of the proportion of fires or the burnt area and the proportion of the given stand type. Based on the value of the cumulative index (formula below), it is possible to classify the stand to one of three flammability classes: class A (high flammability), class B (medium flammability), class C (low flammability), according to Table 4.

Table 3. The occurrences of fires depending on the soil cover types and forest flammability indices

\begin{tabular}{|c|c|c|c|c|c|}
\hline \multirow[b]{2}{*}{ Soil cover type } & \multirow{2}{*}{ 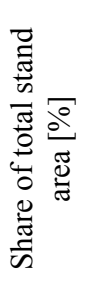 } & \multirow{2}{*}{ 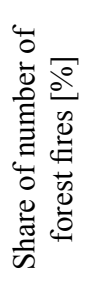 } & \multirow{2}{*}{ 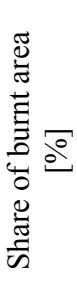 } & \multicolumn{2}{|c|}{$\begin{array}{l}\text { Flammability } \\
\text { index according } \\
\text { to habitat type }\end{array}$} \\
\hline & & & & 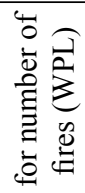 & 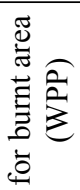 \\
\hline MSZ - moss & 15,43 & 18,78 & 13,38 & 1,22 & 0,87 \\
\hline MSZC - moss/bilberry & 11,53 & 5,33 & 5,16 & 0,46 & 0,45 \\
\hline NAGA - bare & 0,42 & 0,65 & 1,03 & 1,53 & 2,44 \\
\hline SZAD - turf (dense) & 16,34 & 12,89 & 19,29 & 0,79 & 1,18 \\
\hline $\mathrm{SZCH}$ - weed (dense) & 8,65 & 5,12 & 6,93 & 0,59 & 0,80 \\
\hline ŚCIO - litter & 4,01 & 4,47 & 4,36 & 1,11 & 1,09 \\
\hline $\mathrm{ZAD}$ - turf & 57,09 & 48,18 & 45,81 & 0,84 & 0,80 \\
\hline ZIEL - herbaceous & 13,48 & 4,60 & 4,04 & 0,34 & 0,30 \\
\hline
\end{tabular}

When elaborating the method, the weight of the indices was determined by the correlation strength of the density of fires or burnt area along with the existence of the selected stand habitat types. Taking the above into account, a formula for the cumulative flammability index was derived:

$$
\begin{aligned}
\mathrm{WS} & =0.8 \times \mathrm{WSL}+0.4 \times \mathrm{WSP}+ \\
& + \text { if }(\mathrm{WPP}>\mathrm{WPL}) 0.3
\end{aligned}
$$

where:

WSL - the flammability index of forest habitat types for the number of fires,

WSP - the flammability index of forest habitat types for the burnt area,

WPL - the flammability index of forest soil cover types for the number of fires,

WPP - the flammability index of forest soil cover types for the burnt area.
On this basis, it is possible to determine the stand risk class, in accordance with Table 4.

Table 4. The intervals of the cumulative flammability index for the stand flammability classes

\begin{tabular}{|c|c|}
\hline $\begin{array}{c}\text { Value of cumulative } \\
\text { flammability index } W_{S}\end{array}$ & Flammability classes \\
\hline$\geq 1.7$ & A (high) \\
\hline $0.7 \div 1.7$ & B (medium) \\
\hline$\leq 0.7$ & C (low) \\
\hline
\end{tabular}

According to the elaborated method for classification of stand flammability, a risk assessment can be conducted at the sub-compartment level (average area of $3 \mathrm{ha}$ ), compartment level (20 ha) and forest range level (1300 ha). The stand flammability classes for sub-compartment can be generalised to the level of compartment and forest range. It was decided that a generalised class should be a weighted mean of the classes of individual sub-compartments, with the qualification that where the area of the stands of any class exceeded $50 \%$ of the surface of a given area, it was assigned as a whole to that class. The process of classification and mapping for any forest area is fully automated after the selection of forest survey data from the State Forest Information System or Forest Data Bank.

Figure 4 presents an example of forest fire risk mapping according to the stand flammability classes at the compartment level.

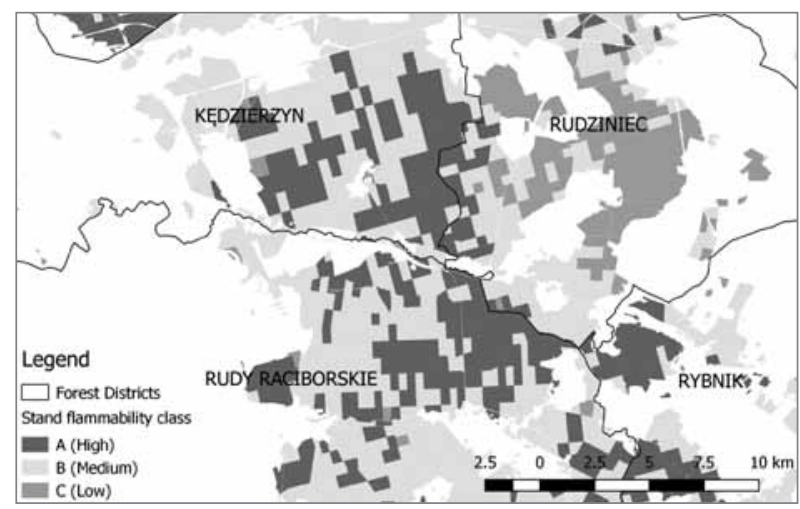

Figure 4. The example of the forest fire risk mapping according to the stand flammability classes at the compartment level 
The classification of stand flammability classes might be used for:

- operational planning and organisation of rescue action for small and medium forest fires (sub-compartment level),
- planning forest fire trails, water supply points and during suppression of large forest fires (compartment level),

- elaboration of the procedures in the event of a forest fire, lookout towers or equipment base localisation (forest range level). 